\title{
Incidence of juvenile Type 1 (insulin-dependent) diabetes mellitus in France
}

\author{
C. Levy-Marchal ${ }^{1}$, L.Papoz ${ }^{2}$, C. de Beaufort ${ }^{1}$, J. Doutreix ${ }^{1}$, V. Froment ${ }^{1}$, J. Voirin ${ }^{1}$, A. Collignon ${ }^{3}$, B. Garros ${ }^{3}$, \\ Y. Schleret ${ }^{3}$ and P. Czernichow ${ }^{4}$ \\ ${ }^{1}$ INSERM Unit 30, Paris, ${ }^{2}$ INSERM Unit 21, Villejuif, ${ }^{3}$ Observatoires Régionaux de Santé and ${ }^{4}$ Hôpital Robert Debré, Paris, France
}

Summary. The incidence rate of juvenile Type 1 (insulindependent) diabetes in France was reported as the lowest in Europe 13 years ago, but during the recent years increasing rates have been observed in different European countries. A prospective programme has been designed to study the incidence rate of Type 1 diabetes in patients up to 20 years of age in four regions located in the north and south of France (population $<20$ years $=2.31$ million inhabitants; $15 \%$ of the French population). All cases were independently identified by four specially trained research assistants through hospital admission files, paediatricians, diabetologists and general practitioners. A specific questionnaire was filled out for each newly diagnosed case. Degree of ascertainment was $96 \%$ with the data from Sécurité Sociale, the French National Health Insurance. In
1988, 166 cases of juvenile Type 1 diabetes were identified. The incidence rate was 7.17 cases per $10^{5}$ children $(95 \%$ confidence interval $\left.=6 \cdot 1-8 \cdot 2 / 10^{5}\right)$. The values were not statistically different among the four regions. Age specific incidence rates were as follows: $0-4$ years $=3.8 ; 5-9$ years $=8.0 ; 10-14$ years $=9.7$ and $15-19$ years $=7.3 / 10^{5}$. Sex ratio was 1.2 (male/female). These data indicate that incidence of juvenile Type 1 diabetes in France was higher in 1988 than previously reported but remains lower than in Northern Europe. This is consistent with the concept of a north to south gradient of the disease.

Key words: Type 1 (insulin-dependent) diabetes mellitus, childhood, incidence rate, geographic pattern, age related pattern, France.
Type 1 (insulin-dependent) diabetes mellitus is a chronic disease occurring during childhood in most cases. Although considerable advances have been made during the last decade, the aetiology of Type 1 diabetes remains unknown.

One puzzling observation is the variation in incidence from one country to another. Such differences have been reported in Europe generating the concept of a northsouth gradient of Type 1 diabetes incidence [1]. Nordic countries exhibit the highest incidence rates $[2,3]$. A Finnish child would have a eight-fold increased risk of developing Type 1 diabetes before the age of 15 [4] compared to a French child.

In France, incidence data were assessed in the 1970's in two different surveys, providing the lowest observed rate in Europe: $3.7 / 10^{5}$ inhabitants under 15 for the whole country, and 4.7 in the area of Lyon $[5,6]$. The method of case catchment differed in the two studies (prospective and retrospective, respectively). This variation in methodology is frequently encountered in incidence studies, mainly due to the location of the surveys and the health care systems, and makes it difficult to comprehend the meaning of the geographical differences. Moreover, Type 1 diabetes incidence has been described as rapidly increasing over the last three decades in some countries in Europe $[3,7,8,9]$ and in North-America [10].

In 1988, a programme was initiated in France to accurately and prospectively document the incidence data of Type 1 diabetes for individuals under the age of 20 . The study was run in four regions with the agreement of the authorities. The purpose was to obtain reliable incidence rates and to establish a data base for other evaluations in the near future.

\section{Subjects and methods}

\section{Case catchment}

Figure 1 shows the four French counties included in the study: Haute-Normandie (West), Basse-Normandie (West), Lorraine (East) and Aquitaine (South), covering an area of $94,800 \mathrm{~km}^{2}(17 \%$ of the total surface area of the country). 


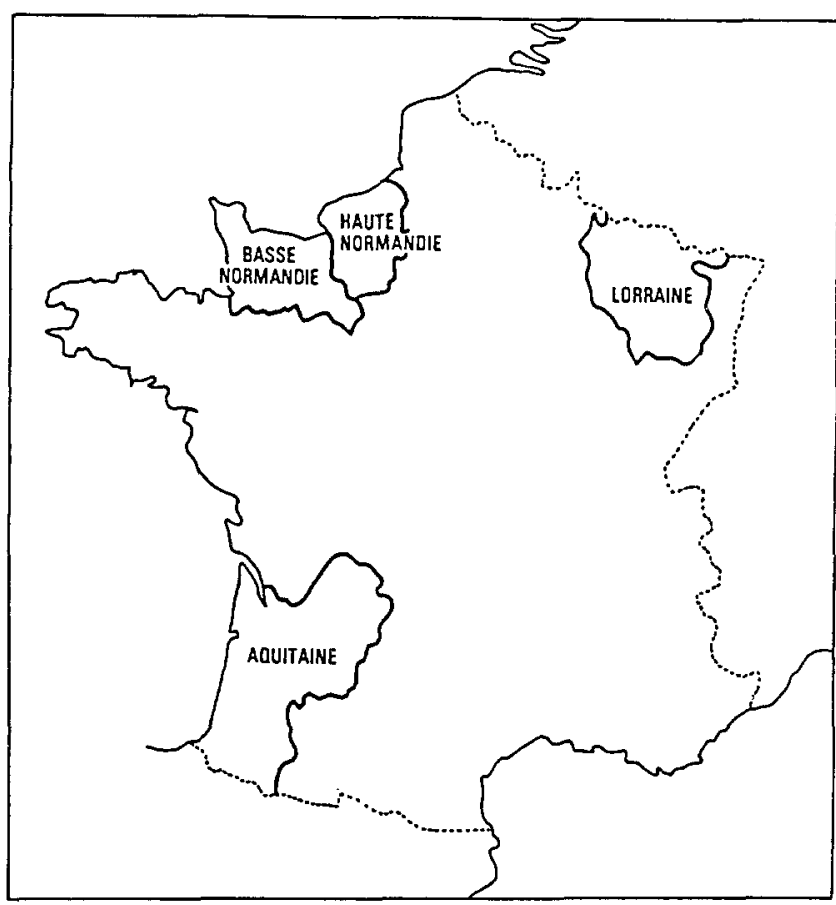

Fig. 1. Map of France with the 4 counties included in the incidence study $\left(94,800 \mathrm{~km}^{2}\right)$

\section{Case definition}

All diabetic patients diagnosed between 1 January and 31 December 1988, and born between 1 January, 1969 and 31 December, 1988 were included. The current address had to be within the defined area, for at least six months prior to diagnosis. Diabetes was defined according to the World Health Organisation criteria [11]. Type 1 diabetes was defined as the presence of ketonuria, (or ketoacidosis) and the need for permanent insulin therapy. The date of the first insulin injection was kept as the date of inclusion in the study. Secondary diabetes and maturity onset diabetes of the young (MODY) were exluded.

\section{Study design}

Case catchment was completed by four research assistants located in each region and specially trained for the study. They were in charge of identifying all the new cases, meeting the families and filling in a specific questionnaire. These questionnaires gathered information on the history of the disease, the initial care and the sociodemo- graphic status of the cases. Ethnicity of a given child was defined by the country of birth of the parents.

Assuming that most of the patients are hospitalized at the onset of insulin therapy in France, we chose the various hospital units for children and adult care (Paediatrics, Diabetology, Internal Medicine, Gastroenterology, Intensive care) as the primary source. In order to ensure an exhaustive census, contact was also established with the private hospitals and the practitioners in private practice (general practitioners and consultants). The frequency and the type of contacts were chosen according to the probability for a given physician to identify a new diabetic case: visits, telephone calls, mail. Moreover, regular meetings were organized in each region, the year prior to and the year of the study, to discuss the protocol and to inform the local physicians about the results of this collaborative work.

All record forms were sent to the central level (INSERM Units) where inclusion criteria, information validity and data analysis were anonymously ascertained by the coordination team.

Approval for the study was obtained from the necessary French authorities (Insitut National de la Santé et de la Recherche Médicale, Caisse Nationale d'Assurance Maladie, Commission Nationale Informatique et Libertés)

\section{Ascertainment}

Data from the French national health insurance, Sécurité Sociale, were elected as the secondary source of information because more than $90 \%$ of the people in the country are registered with this insurance. Either of the parents' insurance covers their childrens' medical expenses. The system is divided into three independent categories according to the professional activity of the individuals (salaried, independent or agricultural activity). The "General Regimen" covers more than $80 \%$ of the French population, e.g. the salaried category. Type 1 diabetes, because it is a chronic disease, benefits from a special reimbursement rate for medical expenses. Therefore, Type 1 diabetic patients are likely to identify themselves to Sécurité Sociale.

Ascertainment over the primary source was performed in collaboration with the physicians of the "General Regimen" of Securite Sociale at each regional level.

\section{Population base}

The population base was calculated using the data from Institut $\mathrm{Na}$ tional de la Statistique et des Etudes Economiques (INSEE). 2.314 million subjects were under the age of 20 years (eg born 1 January, 1969-31 December, 1988) in the four counties with 1.187 million males and 1.127 million females (sex ratio: 1.05 ). They represented about $15 \%$ of the French population under 20 years.

Table 1. Regional incidence rates for Type 1 (insulin-dependent) diabetes in France $(<20$ year-old subjects)

\begin{tabular}{|c|c|c|c|c|c|}
\hline \multirow[t]{2}{*}{ Cases (1988) } & \multicolumn{5}{|l|}{ Regions } \\
\hline & Aquitaine & Lorraine & Basse-Normandie & Haute-Normandie & Total \\
\hline$\overline{\text { Number of cases }}$ & 58 & 49 & 30 & 29 & 166 \\
\hline Population base & 673,508 & 698,026 & 413,303 & 529,917 & $2,314,754$ \\
\hline $\begin{array}{l}\text { Incidence rates } \\
n / 10^{5} / 1988 \\
(95 \% \text { conf. interv. })\end{array}$ & $\begin{array}{l}8.6 \\
(6.4-10.8)\end{array}$ & $\begin{array}{l}7.0 \\
(5.0-9.0)\end{array}$ & $\begin{array}{l}7.3 \\
(4.6-9.9)\end{array}$ & $\begin{array}{l}5.5 \\
(3.4-7.6)\end{array}$ & $\begin{array}{l}7.17 \\
(6.1-8.2)\end{array}$ \\
\hline
\end{tabular}

In each space of the Table are indicated the numbers of patients or inhabitants born between 1 January, 1969 and 31 December, 1988 


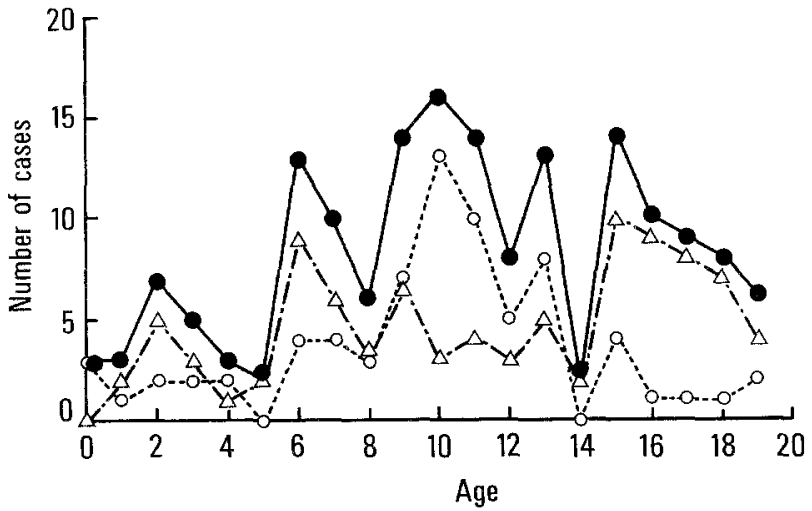

Fig. 2. Occurrence of newly diagnosed Type 1 (insulin-dependent) diabetic cases in 1988 with respect to age at diagnosis. $\bullet$ : total cases; $\triangle---\triangle$ : boys; $O---O$ : girls

\section{Statistical analysis}

Data management and statistical analysis were carried out using a general programme for medical data on the computer VAX 8630 from the National Center for Data Processing of INSERM. Chisquare $\left(\mathrm{X}^{2}\right)$ test was used for comparisons of percentages.

\section{Results}

\section{Incidence rate}

The primary source identified 166 new cases of Type 1 diabetes in 1988. At the time of diagnosis 154 patients were hospitalised, nine were under ambulatory care by private practitioners, and for three cases no information was available. The incidence rate was 7.17 for $10^{5}$ inhabitants under age 20 (95\% confidence interval: $\left.6.1-8.2 / 10^{5}\right)$. There were 141 children of French origin, 18 non-European Caucasian (Northern Africa), six European Caucasian (Southern Europe) and one Black.

More male than female children were newly diagnosed as Type 1 diabetic patients, although the sex ratio $(1.27: 1)$ was not significantly different from the general population. Incidence rates were 7.8 and $6.5 / 10^{5}$ in male and female children respectively. There was no significant variation in incidence according to the regions (Table 1), although the southern region Aquitaine exhibited the highest rate $\left(8.6 / 10^{5}\right)$.

Significant variations in incidence were observed with age $\left(\mathrm{X}^{2}=14.2 ; p<0.01\right)$, youngsters $(0-4$ years $)$ exhibiting the lowest rate $\left(3.8 / 10^{5}\right)$ (Table 2$)$. The annual incidence

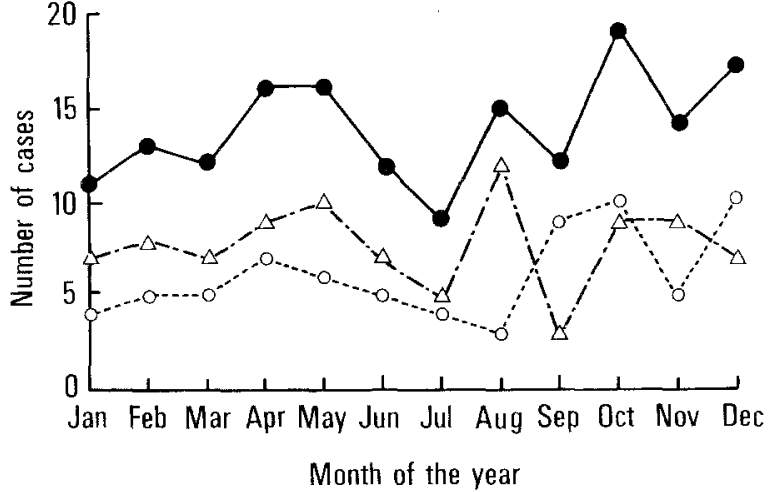

Fig.3. Occurrence of newly diagnosed Type 1 (insulin-dependent) diabetic cases with respect to the month of diagnosis in 1988. total cases; $\triangle---\triangle$ : boys; $\mathrm{O---O:} \mathrm{girls}$

rate was $7.13 / 10^{5}\left(95 \%\right.$ confidence limits: $\left.5.8-8.4 / 10^{5}\right)$ in the age interval $0-14$ years.

Figure 2 shows that the patterns of Type 1 diabetes occurrence with respect to age were not similar in girls and boys. Two cases were diagnosed in girls during the neonatal period and were found to be persistent cases of Type 1 diabetes. The incidence increased gradually to a peak at 10 years, and decreased rapidly thereafter. In boys, several peaks were observed among a rather small number of incident cases during the year of observation, at ages 6 and 10 with a maximum at 15 , followed by a progressive decline thereafter.

No significant variation in incidence was recorded according to the month of diagnosis (Fig. 3).

\section{Ascertainment}

Among the 166 cases, 136 belonged to families registered with the "General Regimen" of Sécurite Sociale. The ascertainment was based on this group. Five additional cases were identified by Sécurité Sociale only, providing a degree of ascertainment of $96 \%$ with the primary source. Therefore, the incidence rate would be $7.39 / 10^{5}$ under 20 years of age. None of the features identified the five children as a group. Apparently, the lack of catchment by the primary source occurred at random. Their age ranged from 10-18 years. Three belonged to Aquitaine and two to Basse Normandie. Two were hospitalized outside the given county and two were hospitalized within the county with a critical and difficult medical history at the time of diagnosis. The last case had inadvertently not been declared by the physician.

Table 2. Age specific incidence rates for Type 1 diabetes in France ( $<20$-year-old subjects)

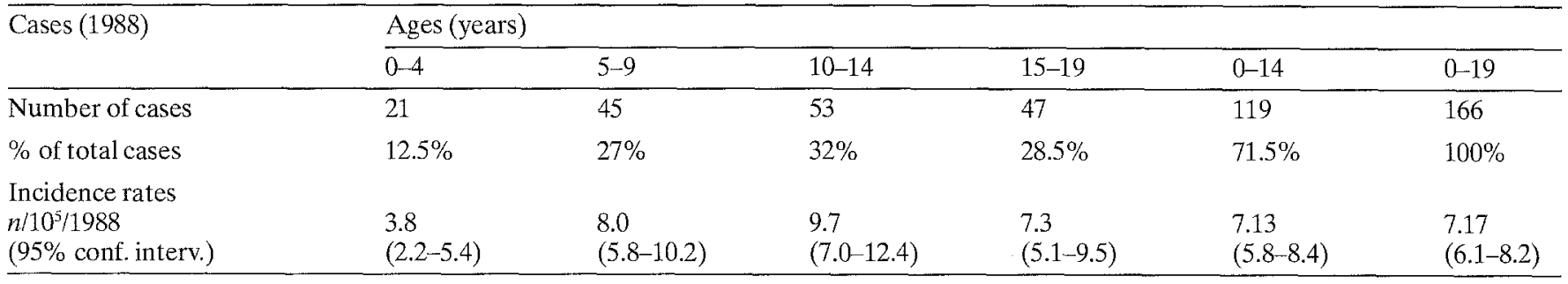




\section{Discussion}

This study has demonstrated an incidence rate of Type 1 diabetes at $7.2 / 10^{5}$ under age 20 and $7.1 / 10^{5}$ under age 15 , higher than previous figures in France, but still low when compared to other countries in Europe.

In one of the previous surveys, showing a value of $3.7 / 10^{5}$ under 15 , the primary source of case catchment was a diabetic association for which registration is voluntary. The other study, restricted to one region (Rhône), was based upon a retrospective analysis of hospital files. The mean yearly rate was $5 / 10^{5}$ children under 15 between 1970-79 [6]. In both studies validation was not made possible with Sécurité Sociale. Since Type 1 diabetes is a rare disease the method of case catchment and the information source for ascertainment are of prime importance for the calculation of incidence rates. Our prospective study was based upon a direct collaboration with any physician likely to diagnose Type 1 diabetes at each regional level.

The goal was easily reached with the numerous hospital units where more than $90 \%$ of the patients were admitted at the onset of insulin therapy. Contacting all of the physicians in private practice $(\approx 15,000)$ was more arduous and critical. All attempts were therefore made to inform the practitioners before and during the study through the medical newspapers, mailings and direct contact, as often as necessary.

Sécurité Sociale provides a reliable secondary source of information because chronic diseases are clearly identified due to $100 \%$ reimbursment for medical expenses. Moreover, the registration with this national health insurance is mandatory in France, especially for salaried people. With the collaboration of Sécurité Sociale, comparison between the two sources of data was extensive in the four regions with a high degree of ascertainment. Therefore, few new diabetic cases are likely to be missed in 1988. Data indicate that the five cases caught by Sécurite Sociale only, and not by the primary source, were not characterized by any special feature, and did not attest for a bias for the catchment of incident cases.

The discrepancy in methodology and case catchment might account for the difference in incidence rates between the 1970's and 1988. The higher rate observed in 1988 in France, however, may also represent temporal increase as it has been reported over the last three decades in some European countries $[3,7,8]$.

The French incidence rate appears to be among the lowest in Europe. Only Poland, a country of the same latitude as France, exhibits a similar rate in a recent prospective study [12]. The rate in Aquitaine $\left(8.6 / 10^{5}\right)$ however was lower than in northern Italy (Aosta valley: $11.6 / 10^{5}$ ) for the same age interval [13] although the latter have been calculated within a very small and specific area. The Lombardy register very recently provided a much lower rate $\left(4.9 / 10^{5}\right)[14]$. The incidence in Lorraine was lower than in Luxembourg (10.6/10 for $0-15$ years) and these two regions are only separated by their border [15]. These data suggest that the overall concept of north-south gradient of incidence may be balanced by some regional clusters.
The different regions in France which our study covered comprised about one fifth of the whole country. France is a country with a wide variety of regional geographic, demographic and climatic features. The four elected counties illustrate this diversity. Lorraine is an industrial area, located inland. Aquitaine has a warm climate with a high wine production. Basse- and Haute-Normandie are both located near the sea with agricultural and mixed agricultural-industrial productions, respectively. Shifts in population are known to occur within a given county. But they were of very little importance outside of the counties (small percentage of the counties populations) when assessed in the early 1980's. Regional differences in incidence rates were observed although they were not significant. This has already been reported in several European countries: Scotland [16], the Netherlands [17], Norway [18], Denmark [19]. However, the lack of statistical significance in the French study may be due to the small number of incident cases recruited over one year of observation, leading to a small power associated with large $95 \%$ confidence intervals. This restriction stands also for age variation of incidence, although most of our results are consistent with previous reports.

The variation of Type 1 diabetes incidence with age has been described in most of the incidence studies. The percentage of cases diagnosed between $0-4$ years was the lowest, similar to that previously reported in France [5,6]. A specific increase in this age group however, has been reported in most recent European surveys $[3,15]$. Our results indicated a peak of Type 1 diabetes occurrence between 9-12 years, around the pubertal age, earlier than that described by Lestradet et al. (11-14 years). This is in keeping with the observations made in Great Britain where Type 1 diabetes prevalence data suggested an earlier diagnosis or manifestation of Type 1 diabetes during childhood without an overall increase in the number of cases [20]. After the pubertal period we observed only a slight decline of the incidence rate (15-19 years: 7.3/10 $)$. In most of the studies related to Type 1 diabetes incidence the age limit for case catchment was 14 years. We deliberately extended this to 19 years. This made the study somewhat more complex because recruitment of cases had to be extended to adult centres. Although the incidence rate in the age group 15-19 years was not different from the total population, a decline was apparent from 15 years onwards. The smaller number of cases in this age group is apparently not due to a mis-catchment. The proportion over the overall incident cases $(47 / 166=28 \%)$ is at the same order of magnitude as previously reported in earlier 0-19 years incidence studies in several European countries, as for example in England [7], Luxembourg [15], the Netherlands [17] and Finland [4]. This pattern argued in favour of a general figure of the Type 1 diabetes incidence as described by Gamble [21] with a rapid increase up to the pubertal peak with progressive decline thereafter, until the age 35-40 years when new cases of the disease are known to be uncommon [22].

Efforts are currently underway to accurately calculate incidence rates of juvenile Type 1 diabetes in many European countries, using a uniform prospective methodology, which would enable values to be established as accurately 
as possible. This work was set up within the framework of the Eurodiab project in which France is taking part. Eurodiab, which is a large project of the European Economic Community on epidemiology of diabetes, will provide an opportunity to validate and perhaps further understand the geographical variation of Type 1 diabetes incidence. As far as temporal variation is concerned our methodology should provide a reliable data base to assess the secular trend for the next decades.

Acknowledgements. We are deeply indepted to all the physicians who generously collaborated with enthusiasm. We are grateful to Dr. J. Marty (Médecin Conseil National), to Drs. Coutin, Diebolt, Lançon, Pannetier (Médecins Conseil Régionaux) and to Drs. Dupon, Fertray, Ingrais (Caisses Régionales d'Assurance Maladie) of the Caisse d'Assurance Maladie de la Sécurité Sociale for their valuable collaboration. Approval from Commission Nationale Informatique et Libertés was obtained in July 1988. This work was supported in part by a collaborative grant from Caisse Nationale d'Assurance Maladie des Travailleurs Salariés and Institut National de la Santé et de la Recherche Médicale (CNAMTS - INSERM \# 998197). We thank Ms. E. Garat for her skillful technical assistance.

\section{References}

1. Laporte RE, Tajima N, Åkerblom HK, Berlin N, Brosseau J, Christy M, Drash AL, Fishbein H, Green A, Hanman R, Harris M, King H, Laron Z, Neil A (1985) Geographic differences in the risk of insulin-dependent diabetes mellitus. The importance of registries. Diabetes Care 8 [Suppl 1]: 101-107

2. Dahlquist $\mathrm{G}$, Gustavsson KH, Holmgren G, Häggluf F, Larsson Y, Nilsson KO, Samnelsson G, Sterky G, Thalme B, Wall S (1982) The incidence of diabetes mellitus in Swedish children 0-14 years of age. A prospective study 1971-1980. Acta Paediatr Scand 71: 7-14

3. Joner G, Søvik O (1989) Increasing incidence of diabetes mellitus in Norwegian children 0-14 years of age, 1973-1982. Diabetologia 32: 79-83

4. Reunanen A, Åkerblom HK, Kaar ML (1982) Prevalence and ten-year (1970-1979) incidence of insulin-dependent diabetes mellitus in children and adolescents in Finland. Acta Paediatr Scand 71: $893-899$

5. Lestradet H, Besse J (1977) Prévalence et incidence du diabète juvénile insulinodépendant en France. Diabète Métab 3:29-34

6. Hours M, Fabry J, Siemiatycki J, Francois R (1984) Diabète insulinodépendant juvénile. Etude descriptive dans le département du Rhône. Rev Epidemiol Santé Publique 32: 107-112

7. Bingley PJ, Gale EAM (1989) Incidence of diabetes mellitus in England: a study in the Oxford region, 1985-6. Br Med J 298: $558-560$

8. Patterson CC, Thorogood M, Smith PG, Heasman MA, Clarke JR, Mann JJ (1983) Epidemiology of Type 1 (insulin-dependent) diabetes in Scotland 1968-1976: evidence of increasing incidence. Diabetologia 24: 238-243
9. Green A, Andersen PK (1983) Epidemiological studies of diabetes mellitus in Denmark 3. Clinical characteristics and incidence of diabetes among males aged 0 to 19 years. Diabetologia 25: 226-230

10. North AF, Growitz K, Sultz HA (1977) A secular increase in the incidence of juvenile diabetes mellitus. Pediatrics 91: 706-710

11. Expert Committee On Diabetes Mellitus (1980) World Health Organization. WHO Technical report series n $n^{\circ} 616$

12. Rewers M, Laporte RE, Walczak M, DmochowskiK, Bogaczynska E (1987) Apparent epidemic of insulin-dependent diabetes mellitus in midwestern Poland. Diabetes 36: 106-113

13. Pagano G, Cavallo-Perin P, Cavalot P, Dall'omo AM, Masciola P, Suriani R, Amoroso A, Curtoni SE, Borelli I, Lenti GF (1987) Genetic, immunologic and environmental heterogeneity of Type 1 diabetes. Incidence and 12 months follow-up of an Italian population. Diabetes 36: 859-863

14. Garancini P, Calori G, Micossi P, Pozza G, Gallus G (1988) Environmental and genetic risk factors for Type 1 (insulin-dependent) diabetes the Lombardy register of incidence cases. Diabetologia 31: 492 (Abstract)

15. De Beaufort C, Michel G, Glaesener G (1988) The incidence of Type 1 (insulin-dependent) diabetes mellitus in subjects aged 0-19 years in Luxembourg: a retrospective study from 1977 to 1986. Diabetologia 31: $758-761$

16. Patterson CC, Smith PG, Webb J, Heashman MA, Mann JI (1988) Geographical variation in the incidence of diabetes mellitus in Scottish children during the period 1977-1983. Diabetic Medicine 5: 160-165

17. Vaandrager GJ, Bruining GJ, Veenhof FJ, Drayer NM (1984) Incidence of childhood diabetes in the Netherlands: a decrease from north to south over North-Western Europe? Diabetologia 27:203-206

18. Joner G, Søvik O (1981) Incidence, age at onset and seasonal variation of diabetes mellitus in Norwegian children. 1973-77. Acta Paediatr Scand 70: 329-335

19. Christau B, Kromann H, Andersen OO (1977) Incidence, seasonal and geographical patterns of juvenile onset, insulin-dependent diabetes in Denmark. Diabetologia 13: 281-284

20. Kurtz Z, Peckham CS, Ades AE (1988) Changing prevalence of juvenile onset diabetes mellitus. Lancet II: $88-90$

21. Gamble DR (1980) The epidemiology of insulin-dependent diabetes with particular reference to the relationship of virus infection to its etiology. Epidemiol Rev 2: 49-70

22. Barker DJP, Gardner MJ, Power C (1982) Incidence of diabetes amongst people aged $18-50$ years in nine British towns: a collaborative study. Diabetologia; 22: 421-425

Received: 27 November 1989

and in revised form: 15 February 1990

Dr. C. Levy-Marchal

Service de Diabétologie Pédiatrique

Hôpital Robert Debré

48, Bd Sérurier

F-75019 Paris

France 